\title{
How Much Do Focal Infarcts Distort White Matter Lesions and Global Cerebral Atrophy Measures?
}

\author{
Xin Wang ${ }^{a}$ Maria C. Valdés Hernández ${ }^{b}$ Fergus Doubal $^{b}$ \\ Francesca M. Chappell ${ }^{\mathrm{b}}$ Joanna M. Wardlaw ${ }^{\mathrm{b}}$ \\ ${ }^{a}$ School of Medicine and Veterinary Medicine, and bivision of Clinical Neurosciences, Brain Research Imaging \\ Centre, University of Edinburgh, Edinburgh, UK
}

\section{Key Words}

White matter disease $\cdot$ Infarcts $\cdot$ Lacunes $\cdot$ Atrophy

Magnetic resonance imaging

\begin{abstract}
Background: White matter lesions (WML) and brain atrophy are important biomarkers in stroke and dementia. Stroke lesions, either acute or old, symptomatic or silent, are common in older people. Such stroke lesions can have similar signals to WML and cerebrospinal fluid (CSF) on magnetic resonance (MR) images, and may be classified accidentally as WML or CSF by MR image processing algorithms, distorting WML and brain atrophy volume from the true volume. We evaluated the effect that acute or old stroke lesions at baseline, and new stroke lesions occurring during follow-up, could have on measurement of WML volume, cerebral atrophy and their longitudinal progression. Methods: We used MR imaging data from patients who had originally presented with acute lacunar or minor cortical ischaemic stroke symptoms, recruited prospectively, who were scanned at baseline and about 3 years later. We measured WML and CSF volumes $(\mathrm{ml})$ semi-automatically. We manually outlined the acute index stroke lesion (ISL), any old stroke lesions present at baseline, and new lesions appearing de novo during fol-
\end{abstract}

low-up. We compared baseline and follow-up WML volume, cerebral atrophy and their longitudinal progression excluding and including the acute ISL, old and de novo stroke lesions. A non-parametric test (Wilcoxon's signed rank test) was used to compare the effects. Results: Among 46 patients (mean age 72 years), 33 had an ISL visible on MR imaging (median volume $2.05 \mathrm{ml}$, IQR $0.88-8.88$ ) and 7 of the 33 had old lacunes at baseline: WML volume was $8.54 \mathrm{ml}$ (IQR 5.86-15.80) excluding versus $10.98 \mathrm{ml}$ (IQR 6.91-24.86) including ISL $(p<0.001)$. At follow-up, median 39 months later (IQR 30-45), 3 patients had a de novo stroke lesion; total stroke lesion volume had decreased in 11 and increased in 22 patients: WML volume was $12.17 \mathrm{ml}$ (IQR 8.54-19.86) excluding versus $14.79 \mathrm{ml}$ (IQR 10.02-38.03) including total stroke lesions $(p<0.001)$. Including/excluding lacunes at baseline or follow-up also made small differences. Twentytwo of the 33 patients had tissue loss due to stroke lesions between baseline and follow-up, resulting in a net median brain tissue volume loss (i.e. atrophy) during follow-up of $24.49 \mathrm{ml}$ (IQR 12.87-54.01) excluding versus $24.61 \mathrm{ml}$ (IQR 15.54-54.04) including tissue loss due to stroke lesions $(p<$ 0.001 ). Including stroke lesions in the WML volume added substantial noise, reduced statistical power, and thus increased sample size estimated for a clinical trial. Conclusions: Failure to exclude even small stroke lesions distorts

\section{KARGER}

Fax +41613061234

E-Mail karger@karger.ch

www.karger.com
(C) 2012 S. Karger AG, Basel

1015-9770/12/0346-0336\$38.00/0

Accessible online at:

www.karger.com/ced
Prof. J.M. Wardlaw

Division of Clinical Neurosciences, Western General Hospital

Crewe Road

Edinburgh EH4 2XU (UK)

E-Mail joanna.wardlaw@ed.ac.uk 
WML volume, cerebral atrophy and their longitudinal progression measurements. This has important implications for design and sample size calculations for observational studies and randomised trials using WML volume, WML progression or brain atrophy as outcome measures. Improved methods of discriminating between stroke lesions and WML, and between tissue loss due to stroke lesions and true brain atrophy are required.

Copyright $\odot 2012$ S. Karger AG, Basel

\section{Introduction}

White matter lesions (WML) are common in older people and in patients with stroke [1] and are associated with cognitive impairment and dementia, particularly in those with WML progression [2-4]. WML are of increased signal on $\mathrm{T}_{2}$-weighted and fluid-attenuated inversion recovery (FLAIR) magnetic resonance (MR) imaging and decreased on $\mathrm{T}_{1}$-weighted relative to normal white and grey matter. Lacunes, small cavities filled with cerebrospinal fluid (CSF) in the basal ganglia, deep white matter or brain stem and often asymptomatic, are also associated with advancing age, stroke, cognitive decline [2] and are part of the spectrum of small vessel disease. Cerebral infarcts, cortical or subcortical, symptomatic or silent [5] occur in approximately one-third to one half of older people on scanning, indicating that silent lesions are more frequent than clinically evident stroke [6]. Stroke lesions may be present at entry to a study, either as an acute symptomatic stroke lesion visible as hyperintense signal on diffusion imaging (index stroke lesions; ISL), old lesions including lacunes present on the baseline scan, or appear de novo during followup. The resulting brain lesions may have similar signals to WML on several MR sequences or result in tissue loss and replacement by CSF. WML volume is used increasingly as an outcome measure in clinical trials and observational studies. The similar signal characteristics of WML and stroke lesions mean that the latter may accidentally be included when measuring the burden of small vessel disease in the form of WML volume using image processing algorithms, resulting in distortion of the WML volume.

Brain atrophy is also common with advancing age and associated with cognitive decline and dementia. The global cerebral atrophy rate in Alzheimer's disease (2-3\% per year) is higher than in healthy controls $(0.2-0.5 \%)$ [7-9]. Cerebral atrophy rates can be measured as brain volume decreases, or CSF increases, using serial regis- tered MR imaging and could be used as a surrogate marker to predict cognitive decline or monitor disease progression. However, measurement of brain atrophy rate could be distorted by tissue loss caused by focal tissue loss following stroke, either cortical or subcortical by formation of lacunes (subcortical rounded or ovoid cavities between 3 and $15 \mathrm{~mm}$ in diameter with the same intensity as CSF on all brain scan sequences [10]), where replacement of damaged tissue by CSF, if included in the global brain volume measurement, would artificially inflate the brain atrophy measurement.

We evaluated the effect that the ISL, any old lesions at baseline and new stroke lesions appearing during followup could have on measurement of WML volume, cerebral atrophy and their longitudinal progression.

\section{Materials and Methods}

We used imaging data from patients with clinical features of a lacunar or mild cortical stroke who were recruited prospectively in a study of stroke mechanisms, details published previously [11]. From the 97 patients (51 lacunar stroke and 46 with cortical stroke) who were recruited into the original study soon after presenting to hospital with an acute stroke, 46 patients ( 22 with the original diagnosis of lacunar stroke and 24 with the original diagnosis of cortical stroke) returned after a median of 39 months (IQR 30-45 months) for follow-up scanning. All patients were assessed by a trained stroke physician and underwent diagnostic magnetic resonance imaging (MRI) with $\mathrm{T}_{1^{-}}, \mathrm{T}_{2}{ }^{*}-\mathrm{T}_{2}$-weighted, diffusion-weighted imaging and FLAIR imaging as described previously [11]. About 3 years later, we performed repeat MRI on the same 1.5-T MR scanner with identical $\mathrm{T}_{1}$ sagittal, $\mathrm{T}_{2}$, FLAIR and gradient recalled echo axial sequences as obtained at baseline. The study was approved by the Lothian Research Ethics Committee and all patients gave written informed consent.

\section{Image Processing}

All image processing was performed blind to all clinical and other imaging data. Baseline and follow-up images were analyzed separately and blind to each other's results. The intracranial volume (ICV), ISL, any old infarcts including lacunes at baseline and new cortical or subcortical stroke lesions appearing at follow-up were manually outlined (masked) on FLAIR, guided by diffusionweighted and $\mathrm{T}_{2}$-weighted images using a region-growing algorithm in Analyze 9.0 software [12]. CSF and WML volumes (ml) were measured using MCMXXXVI [12], a validated image processing algorithm for semiautomatic brain tissue segmentation (http://sourceforge.net/projects/bric1936/). WML progression is the volume difference between follow-up and baseline scans. Brain volume was obtained by subtracting CSF from ICV, and cerebral atrophy was assessed by brain volume decrease or CSF increase between two time points. The tissue loss due to ISL was calculated by combining the baseline ISL mask with the follow-up CSF mask, the overlapping tissue between those two masks was considered as tissue change due to the ISL. 
Statistical Analysis

The distribution of ICV, CSF, WML, stroke lesions and lacunes were not normal (on Kolmogorov-Smirnov tests and inspection of histograms). We expressed absolute lesion volumes in millilitres and also adjusted for intersubject differences in head size using the ICV. Numeric variables were expressed as median (IQR). We compared WML excluding ISL and/or old lesions/lacunes with WML including ISL and/or old lesions/lacunes (to test if the lacunes, a part of small vessel disease, made a material difference to the WML volume), and cerebral atrophy excluding versus including tissue loss due to ISL and/or old lesions/lacunes, using non-parametric tests (Wilcoxon's signed rank test), considering $\mathrm{p}<0.05$ as statistically significant. Statistical analysis was performed with the Statistical Package for the Social Sciences, Version 16.0 (SPSS, Chicago, Ill., USA). G* Power 3 was used for sample size calculations [13].

\section{Results}

Among the 46 patients recruited, at baseline the mean age was 68 years (SD \pm 11$), 30$ (66\%) had hypertension, 4 (13\%) had diabetes, 23 (50\%) were lacunar subtype, median baseline National Institutes of Health Stroke Scale (NIHSS) was 2 (IQR 1-3).

\section{Stroke Lesions}

At baseline, 33 (72\%) had an ISL visible on MRI, median volume $2.05 \mathrm{ml}$ (IQR 0.88-8.88). The median time to follow-up MR was 39 months (IQR 30-45). Three patients had new stroke lesions on follow-up imaging. The stroke lesion volume decreased in 11 and increased in 22 patients between baseline and follow-up to give a median follow-up total stroke lesion volume of $2.43 \mathrm{ml}$ (IQR $0.66-$ 13.42). However, the volume change ranged from $39.14 \mathrm{ml}$ smaller than to $79.97 \mathrm{ml}$ larger than the stroke lesion baseline volume (fig. 1; online suppl. table S1, see www. karger.com/doi/10.1159/000343226 for all online suppl. material). Seven of the 33 patients (15\% of total patients) had an ISL plus one or more lacunes at baseline. The median baseline lacune volume was $0.30 \mathrm{ml}$ (IQR 0.17-0.47). Lacune volume decreased in 2 patients and increased in 5 patients during follow-up to give a median follow-up lacune volume of $0.43 \mathrm{ml}$ (IQR 0.16-0.54). Twenty-two of the 33 patients ( $48 \%$ of total patients) had tissue loss due to ISL. The median baseline tissue loss due to ISL was $0.011 \mathrm{ml}$ (IQR 0.00-0.24), and this decreased in 3 patients and increased in 19 patients during follow-up to give a median follow-up volume of $0.96 \mathrm{ml}$ (IQR 0.07-2.95).

\section{Effect of Stroke Lesions on WML Volume}

Among all 46 patients (online suppl. table S2), the median baseline WML volume was $8.54 \mathrm{ml}$ (IQR 5.86-15.80) excluding, and $10.98 \mathrm{ml}$ (IQR 6.91-25.00) including stroke lesions (difference $Z=-5.012, p<0.001$ ). At followup, the median WML volume was $12.17 \mathrm{ml}$ (IQR 8.5419.86) excluding and $14.87 \mathrm{ml}$ (IQR 10.02-38.67) including the baseline and any new stroke lesions (difference $\mathrm{Z}=-4.937, \mathrm{p}<0.001$ ). Including/excluding just lacunes alone at baseline or follow-up also made small but significant differences (online suppl. table S2).

Restricting the analysis to just the 33 patients with stroke lesions at either time point, or the 26 patients with a stroke lesion but no lacunes, or the 7 patients with lacunes (who all also had stroke lesions) gave similar results for the proportional difference in WML volume between including and excluding ISL, lacunes and new stroke lesions as for all 46 patients (online suppl. tables S3, S4, S5). However, the absolute true WML volumes were larger in patients with a stroke lesion (e.g. baseline WML volume $10.15 \mathrm{ml}$, IQR 6.51-18.13) than in those without (e.g. baseline WML volume $6.63 \mathrm{ml}$, IQR 4.62-9.47, online suppl. table S6). When we adjusted for inter-subject differences in intracranial volume, the pattern of results was the same.

Amongst all 46 patients, WML volume increased in 43 and decreased in 3 patients between baseline and followup (range -1.94 to $33.16 \mathrm{ml}$ ) when stroke lesions were excluded. When stroke lesions were included, 40/46 patients had an increase and 6 had a decrease in WML volume, although the median WML volume progression excluding stroke lesions did not differ significantly from that including stroke lesions (difference $\mathrm{Z}=-1.831, \mathrm{p}=$ 0.067). However, for each individual patient, the WML progression was considerably different including versus excluding stroke lesions, with the potential difference in WML volume progression being huge, ranging from -35.78 to $78.79 \mathrm{ml}$ (fig. 1, 2) or between -208.75 and $163.83 \%$ of the baseline WML volume, as shown in the increasing length of the IQRs, from WML volume excluding stroke lesions (e.g. 11.55) to including stroke lesions in the WML volume (e.g. 20.21; table 1). Thus including the stroke lesions adds substantial noise to the measurement of baseline, follow-up and progression of WML volume.

\section{Effect of Stroke Lesions on Atrophy}

Among all 46 patients, median brain tissue volume excluding the stroke lesions was 1,155.16 $\mathrm{ml}$ (IQR 1,069.971,250.78) at baseline and $1,127.66 \mathrm{ml}$ (IQR 1,054.82- 
Fig. 1. Variation in WML volume at baseline, follow-up and progression due to excluding/including stroke lesions (SL, acute or old) at baseline and new lesions appearing at follow-up.

Fig. 2. Three slices from the same patient showing the influence of stroke lesions (SL) at baseline and new stroke lesions appearing during follow-up on WML volume measurements at baseline, follow-up and combined scans.
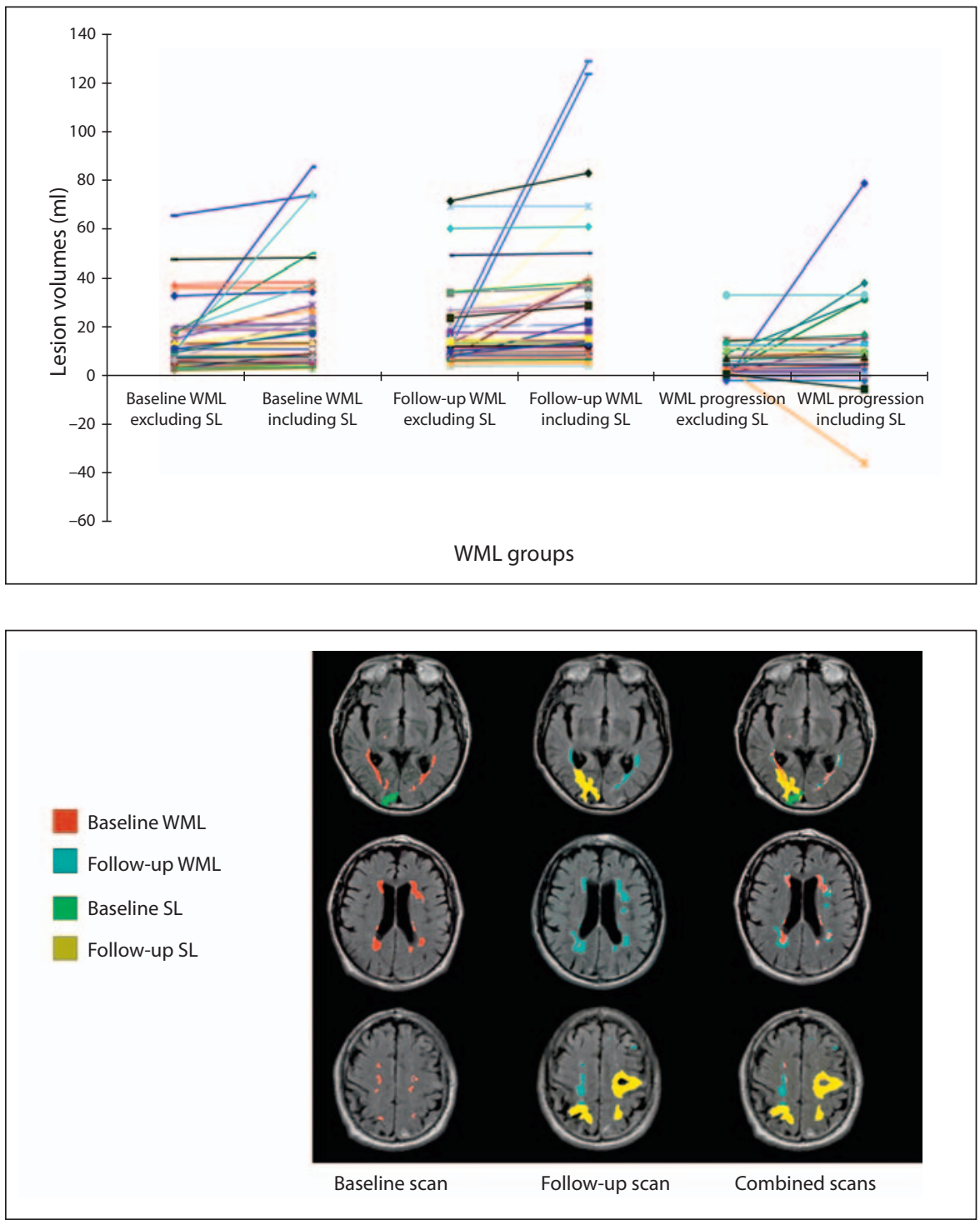

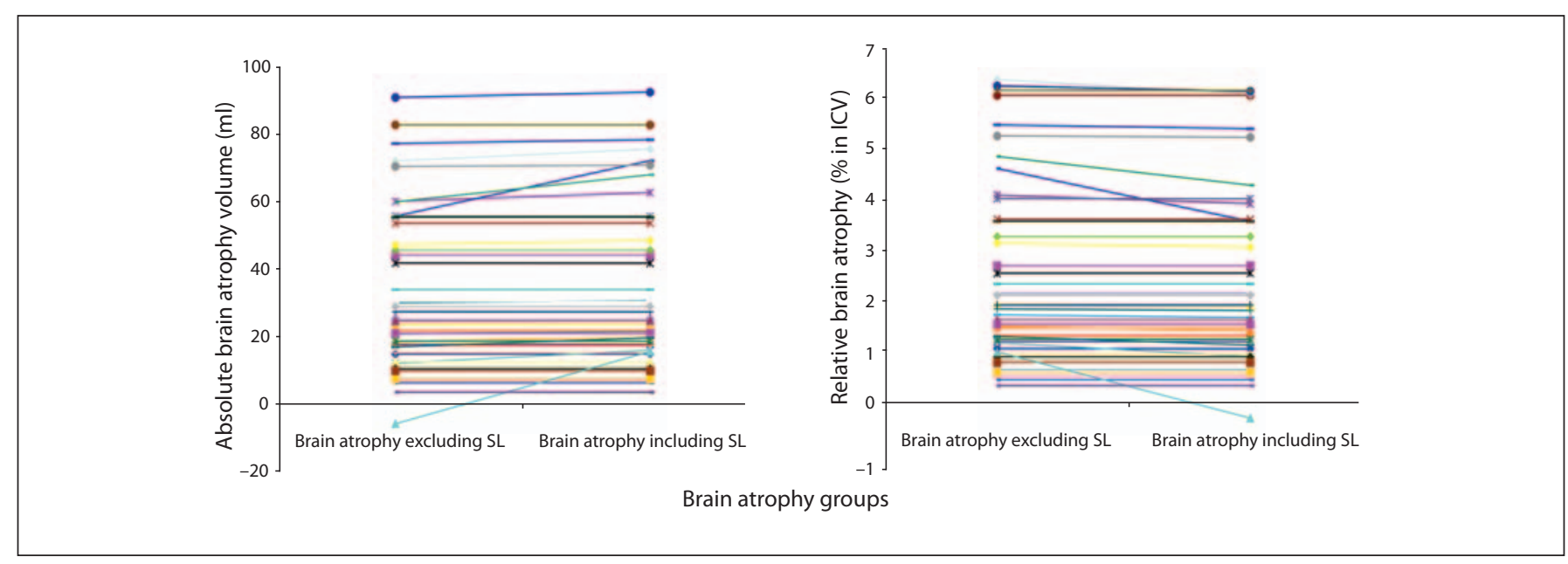

Fig. 3. Estimation of absolute and relative brain atrophy excluding and including the stroke lesions (SL). 
Table 1. Effect of the stroke lesions (SL) on WML volume IQR at baseline and follow-up and estimates of volume change

\begin{tabular}{llr}
\hline Group & Variable & Length of IQR, ml \\
\hline Patients with WML only $(\mathrm{n}=13)$ & WML at baseline & 2.88 \\
Patients with stroke lesions $(\mathrm{n}=33)$ & WML at baseline & 11.55 \\
Patients with stroke lesions $(\mathrm{n}=33)$ & WML + SL at baseline & 20.21 \\
\hline Patients with WML only $(\mathrm{n}=13)$ & WML at follow-up & 5.26 \\
Patients with stroke lesions $(\mathrm{n}=33)$ & WML at follow-up & 13.57 \\
Patients with stroke lesions $(\mathrm{n}=33)$ & WML + SL at follow-up & 26.08 \\
\hline Patients with WML only $(\mathrm{n}=13)$ & difference in WML & 4.90 \\
Patients with stroke lesions $(\mathrm{n}=33)$ & difference in WML & 6.14 \\
Patients with stroke lesions $(\mathrm{n}=33)$ & difference in WML $+\mathrm{SL}$ & 9.83 \\
\hline
\end{tabular}

1,204.77) at follow-up; including the stroke lesions it was $1,154.35 \mathrm{ml}$ (IQR 1,069.97-1,250.63) at baseline and 1,127.66 ml (IQR 1,052.26-1,204.76) at follow-up. Expressed in terms of brain atrophy, the median brain atrophy volume was $24.49 \mathrm{ml}$ (IQR 12.87-54.01) excluding and $24.61 \mathrm{ml}$ (IQR 15.54-54.04) including the stroke lesions (Wilcoxon's signed rank test, $\mathrm{Z}=-3.915, \mathrm{p}<0.001$ ).

When expressed as a percentage of ICV, the median percentage of brain tissue volume in the ICV excluding the stroke lesions was $81.04 \%$ (IQR 79.16-83.25) at baseline and 78.45\% (IQR 76.04-81.87) at follow-up; including the stroke lesions was $81.03 \%$ (IQR 79.15-83.25) at baseline (Wilcoxon's signed rank test, $\mathrm{Z}=-3.724$, $\mathrm{p}<$ 0.001 ) and $78.32 \%$ (IQR 75.63-81.83) at follow-up (Wilcoxon's signed rank test, $\mathrm{Z}=-4.372, \mathrm{p}<0.001$ ).

For all 46 patients, the median stroke lesions volume change between baseline and follow-up was $0.00 \mathrm{ml}$ (IQR $0.00-0.81$ ). For the 22 patients with tissue loss due to the ISL, the median ISL volume change was $0.90 \mathrm{ml}$ (IQR 0.05-2.89), with volume differences between true brain atrophy volume (excluding effect of the ISL) and apparent brain atrophy volume (including effect of the ISL) ranging from $0.05 \mathrm{ml}$ less to $21.25 \mathrm{ml}$ more than the true brain atrophy volume. This represents up to $1.65 \%$ of the baseline brain tissue volume, or up to 4 -fold more than true brain atrophy (fig. 3).

For all 46 patients, the median progression of brain atrophy as a percentage of ICV was $1.73 \%$ (IQR 0.92-3.55) excluding versus $1.77 \%$ (IQR 1.03-3.56) including the stroke lesions. For the 22 patients with tissue loss due to the ISL, the median brain atrophy as a percentage of ICV was $2.03 \%$ (IQR $1.35-4.50$ ) excluding versus $2.03 \%$ (IQR 1.44-4.94) including the ISL.
Effect of Stroke Lesions on Sample Size in Studies of WML as an Outcome Measure

We estimated sample size for a trial of the effect of a drug on WML progression, assuming a $20 \%$ reduction in WML progression with active drug, from $30 \%$ in the control group to $24 \%$ in the treated group. At $80 \%$ power and alpha of 0.05 , the trial would require 1,730 patients based on WML volume excluding stroke lesions and 3,623 patients if the stroke lesions were included in the WML volume this difference being largely driven by the larger IQR of WML volume when including the stroke lesions.

\section{Discussion}

WML and brain atrophy are of increasing interest in studies of ageing, stroke and dementia. In this fairly typical cohort of patients who had originally presented with an acute lacunar or cortical mild stroke [11], we demonstrated that failure to account for stroke lesions when measuring WML volume could increase significantly both median baseline and follow-up WML volume by about $20 \%$ and added substantial noise to the measurement of WML progression. Similarly, for individual patients, failing to consider the stroke lesions when measuring brain atrophy could increase apparent brain volume loss by up to $21.25 \mathrm{ml}$ more than true brain atrophy volume, representing $1.65 \%$ of baseline brain volume, or up to 4 times more than true brain atrophy. As WML and atrophy are commonly present together in brains of older people [14] as are clinically apparent and silent infarcts [15], failure to exclude stroke lesions from measures of 
both WML and atrophy could confound substantially any studies assessing any correlation between risk factors for or treatments to prevent stroke, WML and delay atrophy. For example, one might think that a drug to prevent cardioembolic stroke was reducing WML progression when in fact it was preventing recurrent ischaemic stroke but not influencing WML progression at all.

We demonstrate an important consideration for longitudinal studies of WML, brain atrophy and randomised trials of treatments to prevent WML progression or brain atrophy, by showing that failure to exclude the stroke lesions, even though for example the median ISL volume was small ( $2.05 \mathrm{ml}$ at baseline, $2.43 \mathrm{ml}$ at follow-up), could lead to very misleading estimates of WML volumes and brain atrophy. Including the stroke lesions in the WML volumes adds noise to the WML data at baseline, followup and estimates of progression, resulting in loss of statistical power. Acute or old stroke lesions may be present at entry to a study, may shrink in size or increase and new stroke lesions may appear during follow-up. Thus, for the individual patient, the effect on WML volume progression is huge and impossible to predict on an individual basis if stroke lesions are included because of the large negative or positive effects of the stroke lesions change. Reassuringly, the specific effect of lacunes alone on the longitudinal WML measurements was small and can probably be ignored unless present in large numbers. Including the stroke lesions in measurement of atrophy also adds noise to the brain tissue volume at baseline, followup and estimation of progression.

This has important implications for design and in particular for sample size calculations for observational studies and randomised trials using WML volume, WML volume progression or brain atrophy as an outcome measure. Statistical power is driven by the IQR, a measure of 'noise' in the system, as well as by the absolute difference between groups that one is trying to detect. The added noise from stroke lesions and consequent more than doubling of the sample size would substantially increase trial duration and costs. Failing to exclude stroke lesions from WML volume measurement could obscure the effect of treatment on WML progression and mean that potentially effective treatments would be missed in error or make ineffective treatments look as if they were beneficial. Visual WML rating scales avoid the problem of infarcts contaminating the WML volume. However, they are less sensitive to small changes in WML burden than are WML volume measures, assuming that the latter are accurate. Use of both WML visual scores and volumes in a study would help identify discordant volume values that might help avoid confounding of WML volume by stroke lesions.

The strengths of this study include the use of a representative cohort of patients with a wide range of severities of WML. The analyst was blinded to all clinical information. We used a carefully tested WML and CSF volume measurement method (MCMXXXVI) [12] that combines information from two sequences to reduce errors in WML and CSF detection. A neuroradiologist identified the infarcts and lacunes and distinguished them from WML for image processing.

The study limitations include that the results may not apply to patients with multiple lacunes as only 7 patients had a few lacunes. Our population had more stroke lesions than in similarly aged subjects without a history of stroke, although silent cortical and subcortical stroke lesions and lacunes occur in up to $75 \%$ of otherwise asymptomatic older volunteers $[6,16,17]$. It was sometimes difficult to distinguish the edge of the stroke lesions from the WML, but we performed the analysis blind to all other factors so that any bias is likely to be minimal.

Further studies are needed to determine the full magnitude of the effect that stroke lesions and lacunes could have on WML and cerebral atrophy measurement, and find better ways of discriminating between stroke lesions and WML and between tissue loss due to stroke lesions and true brain atrophy.

\section{Acknowledgements}

This study was supported by the Chief Scientist Office of the Scottish Executive (CZB/4/281) (J.M.W.), the Wellcome Trust (075611) (F.D., J.M.W.), Chest Heart Stroke Scotland (J.W.), the Row Fogo Charitable Trust (M.C.V.H., J.M.W.), the Cohen Charitable Trust (J.M.W.) and China Scholarships Council/University of Edinburgh Scholarships scheme (X.W.).

The scans and associated data collection were funded by the Chief Scientist Office of the Scottish Executive and the Center for Cognitive Ageing and Cognitive Epidemiology (http://www. ccace.ed.ac.uk/). The imaging was conducted at the Brain Research Imaging Centre, University of Edinburgh (http://www. bric.ed.ac.uk/).

\section{Disclosure Statement}

Nothing to report. 


\section{References}

$>1$ Debette S, Markus HS: The clinical importance of white matter hyperintensities on brain magnetic resonance imaging: systematic review and meta-analysis. BMJ 2010; 341:c3666.

-2 Cavalieri M, Schmidt R: New development in diagnosis of vascular cognitive impairment. J Neurol Sci 2010;299:11-14.

>3 Longstreth WT Jr, Arnold AM, Beauchamp NJ Jr, Manolio TA, Lefkowitz D, Jungreis C, Hirsch CH, O'Leary DH, Furberg CD: Incidence, manifestations, and predictors of worsening white matter on serial cranial magnetic resonance imaging in the elderly: the Cardiovascular Health Study. Stroke 2005;36:56-61.

4 Schmidt R, Ropele S, Enzinger C, Petrovic K, Smith S, Schmidt H, Matthews PM, Fazekas F: White matter lesion progression, brain atrophy, and cognitive decline: the Austrian stroke prevention study. Ann Neurol 2005; 58:610-616.

5 Vermeer SE, Longstreth WT Jr, Koudstaal PJ: Silent brain infarcts: a systematic review. Lancet Neurol 2007;6:611-619.

6 Esiri MM, Matthews F, Brayne C, Ince PG, Matthews FE, Xuereb JH, Broome JC, McKenzie J, Rossi M, McKeith IG, Lowe J, Morris JH: Pathological correlates of late-onset dementia in a multicentre, communitybased population in England and Wales. Lancet 2001;357:169-175. $\checkmark 7$ Fox NC, Scahill RI, Crum WR, Rossor MN: Correlation between rates of brain atrophy and cognitive decline in AD. Neurology 1999;52:1687-1689.

-8 Fox NC, Warrington EK, Rossor MN: Serial magnetic resonance imaging of cerebral atrophy in preclinical Alzheimer's disease. Lancet 1999;353:2125.

9 Fox NC, Schott JM: Imaging cerebral atrophy: normal ageing to Alzheimer's disease. Lancet 2004;363:392-394.

10 Potter GM, Marlborough FJ, Wardlaw JM: Wide variation in definition, detection, and description of lacunar lesions on imaging. Stroke 2011;42:359-366.

11 Wardlaw JM, Doubal F, Armitage P, Chappell F, Carpenter T, Munoz MS, Farrall A, Sudlow C, Dennis M, Dhillon B: Lacunar stroke is associated with diffuse blood-brain barrier dysfunction. Ann Neurol 2009;65: 194-202.

12 Hernandez MC, Ferguson KJ, Chappell FM, Wardlaw JM: New multispectral MRI data fusion technique for white matter lesion segmentation: method and comparison with thresholding in FLAIR images. Eur Radiol 2010;20:1684-1691.
13 Erdfelder E, Faul F, Buchner A: GPOWER: a general power analysis program. Behav Res Meth Instrum Comput 1996;28:1-11.

14 Appelman AP, Exalto LG, van der GY, Biessels GJ, Mali WP, Geerlings MI: White matter lesions and brain atrophy: more than shared risk factors? A systematic review. Cerebrovasc Dis 2009;28:227-242.

15 Liou LM, Chen CF, Guo YC, Cheng HL, Lee HL, Hsu JS, Lin RT, Lin HF: Cerebral white matter hyperintensities predict functional stroke outcome. Cerebrovasc Dis 2010;29: 22-27.

16 Gorelick PB, Scuteri A, Black SE, DeCarli C, Greenberg SM, Iadecola C, Launer LJ, Laurent S, Lopez OL, Nyenhuis D, Petersen RC, Schneider JA, Tzourio C, Arnett DK, Bennett DA, Chui HC, Higashida RT, Lindquist R, Nilsson PM, Roman GC, Sellke FW, Seshadri S: Vascular contributions to cognitive impairment and dementia: a statement for healthcare professionals from the American Heart Association/American Stroke Association. Stroke 2011;42:2672-2713.

17 Morris Z, Whiteley WN, Longstreth WT Jr, Weber F, Lee YC, Tsushima Y, Alphs H, Ladd SC, Warlow C, Wardlaw JM, Al-Shahi Salman R: Incidental findings on brain magnetic resonance imaging: systematic review and meta-analysis. BMJ 2009;339:b3016. 